\title{
Para UMa Crítica ao PRIMAdo DAS FORÇAS PRODUTIVAS NA ANÁLISE DA FORMAÇÃO DO OPERARIADO EM CLASSE
}

\author{
Henrique Amorim ${ }^{1}$
}

\begin{abstract}
RESUMO
Esse artigo pretende discutir a formação do operariado em classe. Para tal, faremos a análise crítica das teorias que se valem da homogeneidade política dos trabalhadores da indústria, do caráter revolucionário do operariado politécnico nos anos 1960 e 1970 na Europa, bem como do trabalho imaterial como força produtiva central hoje. A caracterização da estrutura de classes e, em especial, da classe revolucionária define-se nessas correntes teóricas com base na determinação geral do primado das forças produtivas. 0 desenvolvimento dessas forças (no interior da perspectiva do progresso técnico) respaldou, e parece ainda respaldar, as análises da sociologia dominante quanto à formação da classe operária e de sua superação na atualidade. Aqui, exporemos criticamente três teorias que são exemplos desse determinismo analítico, fundamentando, sobretudo, os seus limites.

Palavras-chave: Classe operária. Trabalho imaterial. Forças produtivas.
\end{abstract}

\footnotetext{
${ }^{1}$ Pós-Doutorando em Sociologia e Doutor em Ciências Sociais pela Universidade Estadual de Campinas (UNICAMP). Email: henriqueamorim@hotmail.com.
} 


\begin{abstract}
This article attempts to discuss the formation of the workers as a class. To that end, we will critically analyze the theories that focus on the political homogeneity of industrial workers, on the revolutionary character of politechnic workers in the sixties and seventies in Europe, and on Immaterial work. as the central productive force today. The characterization of the class structure and, especially, of the revolutionary class is characterized in those theoretical currents in relation to the general determination of the primacy of productive forces. The development of those forces (within the perspective of technical progress) supported, and seems to continue to support, the analyses of the dominant sociology with regard to the formation of the working class and its obsolescence today. Here we will critically discuss three theories that are examples of that analytical determinism, underscoring principally their limitations.
\end{abstract}

Keywords: Working class. Immaterial work. Productive forces.

\title{
INTRODUÇÃO
}

$\mathrm{D}$ urante o século XX, desenvolveu-se na tradição marxista uma linha de análise que foi encampada por inúmeros autores e que permanece vigorosa no limiar desse novo século. Derivada de uma das teses do 0 Manifesto do Partido Comunista na qual Marx e Engels (1996) facultariam, ao desenvolvimento das forças produtivas, relativa autonomia, sobretudo, por afirmarem a implosão das relações de produção pelo acúmulo dessas forças. Essa linha de análise fundamentou-se, portanto, na sobredeterminação das forças produtivas sobre as relações de produção, caracterizando, assim, o determinismo das primeiras no processo de constituição do operariado em classe.

As teorias da superação histórica do capitalismo sobre a formação do sujeito histórico revolucionário, organizador das novas relações sociais de produção são, assim, marcadas pelo primado do desenvolvimento das forças produtivas sobre as lutas sociais, políticas e ideológicas. Essa discussão vem marcada pelo determinismo da ciência e da técnica no contexto da "formação" do operariado em classe.

Nesse sentido, a "formação" da classe revolucionária é caracterizada não em decorrência de questões históricas específicas de cada sociedade, das condições 
de vida e da organização política das massas, mas sim de um elemento autônomo que facultaria a uma classe ou a um determinado grupo social as possibilidades materiais de superação das relações de produção capitalista.

0 objetivo deste artigo é discutir criticamente três teorias sobre a constituição do operariado em classe (revolucionária). Resgataremos, assim, primeiro as análises de Serge Mallet (1969) sobre a "nova classe operária", posteriormente, as teses de Maurízio Lazzarato (1993) sobre o chamado trabalho imaterial para, por fim, discutir as teses de Décio Saes (2003) sobre os grupos funcionais na ordem capitalista e "aparição" da classe revolucionária dentro de um cenário antagonístico.

Pretendemos explicitar, com isso, o fundamento comum entre estas três teorias sobre a "formação" social do operariado em classe, a saber, dentro de uma perspectiva a-histórica, condicionada à sobredeterminação das forças produtivas como fundamento-chave dessa "formação" e da superação do capitalismo.

\section{Determinismo Tecnológico e a "Nova Classe OPERÁRIA": NOS ANOS 1960 E 1970}

0 debate em torno da questão do avanço tecnológico foi, ao longo das décadas de 1960 e 1970, amplamente discutido, tornando-se um tema central das análises sobre a "formação" da classe revolucionária e da superação do capitalismo. No bojo teórico dessa discussão, o livro La Nouvelle Classe Ouvrière de Serge Mallet (1969), encaminhou sua análise no sentido de determinar o aparecimento de um segmento operário revolucionário relacionado diretamente às novas forças produtivas desenvolvidas com a automação.

Em síntese, esta nova classe surgiria de uma necessidade técnica dentro do processo produtivo. 0 desenvolvimento técnico dos processos de trabalho e das tarefas produtivas acabariam por capacitar politicamente o operariado tecnocientífico. Elementos técnicos superiores forjariam, assim, um sujeito social revolucionário.

Em consequiência do surgimento dessa "nova classe operária", organizarse-ia uma base política a partir da qual se proliferaria uma consciência crítica, não mais corporativa (como a do operariado tradicional), mas sim preocupada em questionar o conjunto das organizações econômicas e sindicais institucionalizadas até então. Esse processo de questionamento tenderia, segundo Mallet, a ultrapassar 
as reivindicações ligadas apenas a uma ou a outra categoria para se insurgir contra o controle da produção na empresa e contra a reprodução do trabalhador assalariado.

Ligado aos setores mais desenvolvidos da produção, esse segmento revolucionário (os operários polivalentes) poderia, com base na aquisição do conhecimento técnico e científico dos setores de ponta, aos quais tinha contato direto, criar uma resistência política e social mais avançada, sobretudo porque esse grupo teria como compromisso o progresso técnico da sociedade, podendo, nesse sentido, persuadir outras classes sociais com sua visão de mundo libertadora.

Vemos aprofundar e precisar a situação absolutamente original da classe operária no interior do mundo capitalista: diferente das classes médias tradicionais, ela não tem nada a defender que não seja seu próprio bem, seu domínio. [...] Uma única via está aberta à sua frente, aquela do progresso (MALLET, 1969, p. 27).

A "nova classe operária" teria, então, a consciência necessária para salvaguardar os interesses gerais consagrados pela politecnia e, assim, poderia desenvolver uma estratégia operária entendida, por Mallet, como única possibilidade de melhoria da relação social entre trabalho e capital. A redefinição do conjunto de reivindicações da classe trabalhadora deveria dar sustento a essa nova classe que se organizaria ao se contrapor às ações do operariado tradicional. Sendo que este questionamento viria, em primeiro lugar, da humanização das relações sociais alicerçadas na desalienação da condição operária no processo de produção e reprodução da força de trabalho e, em segundo, e como conseqüência da primeira, pela prerrogativa científica que fundamentaria a incapacidade política do trabalhador tradicional frente ao trabalhador tecno-científico em constituir uma consciência revolucionária superior (MALLET, 1969, p. 27-33).

A idéia de uma vanguarda que detivesse clareza do processo de produção e também do mercado estimularia, por conseguinte, as lutas sindicais. A ampliação das condições do operariado polivalente faria com que o caráter executor e a hierarquia na produção fossem eliminados e com eles a divisão capitalista do trabalho. Isto tornaria possível superar o antagonismo do trabalho frente ao capital. Nesse sentido, a subsunção real radicalizada com o taylorismo poderia ser superada a partir do binômio automação/polivalência.

Hoje, contrariamente, vemos que a automação não criou indivíduos capazes de gerir o processo de produção de maneira autônoma. Na prática, ela 
acabou por aprofundar a subsunção real do trabalhador ao capital, pois, além de condicionar a força física dos trabalhadores em seu benefício, condicionou-os também intelectualmente. Toda esta suposta emancipação produtiva, que seria dada pela reconquista do saber-fazer nos processos de trabalho ${ }^{2}$, foi condicionada a uma liberdade vigiada.

A "nova classe operária" ainda estava obviamente subsumida à exploração do capital. Ao contrário do que Mallet considerava, o contato com as novas técnicas de produção não acabou com a divisão do trabalho. As mudanças na produção não só reproduziram a mesma natureza do trabalho (assalariada), mas, além disso, radicalizaram a exploração da força de trabalho naquela conjuntura.

0 trabalho continuou sendo assalariado. A natureza do trabalho, dessa forma, não acrescentou nem diminuiu nada à condição de subalternidade da classe trabalhadora frente ao domínio capitalista nos processos de trabalho. Reorganizou-se, sim, a forma de exploração do trabalho. Agora, a participação ativa do trabalhador passou a ser exigida, isto é, a responsabilidade do trabalhador aumentou na medida em que algumas funções ligadas à supervisão, por exemplo, (obviamente, não se tratava de funções diretivas) são a ele conferidas.

Do ponto de vista das organizações capitalistas, a apologia a tais transformações e inovações tecnológicas teria, no nosso entendimento, uma razão justificável: ela abre novos espaços para a exploração da força de trabalho. Já do ponto de vista do operariado, devemos nos perguntar: quais seriam as possibilidades concretas de estruturação de uma luta socialista decorrente do processo de automação das empresas capitalistas? Ou ainda, de que maneira uma determinação científica poderia ser incorporada a uma luta proletária que se pretende socialista?

Em linhas gerais, Mallet condicionou a força política do movimento operário, leia-se, sua capacidade de organização sindical e/ou partidária, a sua qualificação profissional, ao conteúdo/conhecimento técnico advindo do processo de automação das empresas capitalistas. Dessa maneira, a formação técnica desenvolvida e incentivada na própria empresa foi reproduzida teoricamente, já que ela, supostamente, possibilitaria aos trabalhadores especializados uma qualificação política, estabelecendo uma nova e vantajosa relação de força com 0 patronato.

\footnotetext{
${ }^{2}$ Sobre 0 processo de qualificação/desqualificação do trabalhador no processo produtivo, ver Braverman (1980) e Marglin (1996).
} 
A formação da classe revolucionária, portanto, é pensada por Mallet com base nas qualificações técnicas do operariado. Confunde-se classe e luta de classes com categorias profissionais e lutas corporativas. 0 confronto antagonístico e direto entre as classes sociais é reduzido à luta pela repartição da renda ou pela melhoria das condições de trabalho no processo produtivo. Nesse sentido, Mallet pôde interpretar a formação da base material propícia à organização revolucionária a partir da idéia de um moto-contínuo dado pelo desenvolvimento das forças produtivas. Criou, com isso, um automatismo da história que implica em uma análise determinista da superação do capitalismo e da formação do operariado em classe.

No próximo item, apresentaremos como esse tipo de análise reaparece na década de 1990 no debate sobre a imaterialidade do trabalho. Ancorado em uma tentativa de reposta às teses sobre a não-centralidade do trabalho, o trabalho imaterial é apresentado como locus de uma luta operária superior e ampla. Vejamos seus argumentos.

\section{O Trabalho Imaterial e a Formação do Operariado em Classe}

0 debate sobre as formas de exploração do trabalhador coletivo na atualidade engloba alguns eixos de análise que nos parecem interessantes. Um deles caracteriza-se pela discussão em torno do trabalho imaterial. Para os objetivos deste trabalho, essa discussão traz a seguinte assertiva: de maneira mais ampla, o trabalho imaterial sintetiza-se com base na apropriação de informações (do intelecto) do trabalhador que devem ser acionadas no processo de valorização do capital.

Mesmo caracterizando-se como uma forma de exploração social ainda embrionária, esse tipo de produção requer, segundo a literatura especializada, leia-se, por exemplo, Lazzarato (1992, 1993), Negri e Vincent (1992), Tosel (1994), Vincent (1993), entre outros, uma força de trabalho "intelectualizada" que deve contribuir criativamente na formação de novas mercadorias e na reprodução das velhas.

Mas, qual seria a ligação entre a suposta imaterialidade do trabalho com a formação do operariado em classe? Para nós, a problemática caracterizada pela leitura do trabalho imaterial tende a qualificar o operariado imerso ou próximo das profissões ditas imateriais como uma vanguarda, justamente por estar qualificada 
e informada por elementos altamente sofisticados no processo de valorização do capital.

Nesse sentido, o desenvolvimento de redes de comunicação, softwares, hardwares, computadores, sistema de televisão, comunicação, propaganda, engenharia de projetos e muitos outros teriam imposto a necessidade de profissionais altamente qualificados, os quais teriam a possibilidade de questionar estruturalmente as formas de dominação e exploração das classes capitalistas, já que seriam, primeiro, imprescindíveis à elaboração e execução de seu trabalho e, segundo, porque sua qualificação profissional e 0 acesso a informações poderiam lhes garantir a possibilidade de reorganização das relações de produção.

Nesse sentido, Lazzarato apresenta a produção imaterial como produção de um "ciclo" ampliado em contraposição aos preceitos da indústria maquinofatureira. A indústria tradicional daria lugar a uma grande empresa, uma espécie de empresa-sociedade, que não estaria apenas articulada ao local de trabalho, mas à produção de uma informação que se sociabilizaria.

Este "ciclo" da produção imaterial extravasaria o chão de fábrica e tornaria a figura do trabalhador autômato (libertado do tempo de trabalho) uma possibilidade para o conjunto da sociedade capitalista. A abrangência dessa produção e da exploração do trabalho como força produtiva central para a reprodução das relações capitalistas radicalizar-se-ia ao universalizar um tipo de cooperação produtiva que aprofunda a exploração da subjetividade do trabalhador e faz reproduzir a subsunção real de sua condição social.

0 conceito de trabalho imaterial como pressuposto e resultado de um alargamento da 'cooperação produtiva' passa a incluir a produção e a reprodução da comunicação e, portanto, seu conteúdo mais importante: a subjetividade. Se o fordismo integrou o consumo ao ciclo de produção do capital, o pós-fordismo integra a comunicação (LAZZARAT0, 1993, p. 111).

Vislumbra-se, assim, uma ampliação do trabalho imaterial como tendência nas atuais formas de produção capitalistas. Ele aparece, aos olhos de Lazzarato, com a particularidade de inovar as relações de produção e de colocar os trabalhadores inseridos nesse universo produtivo em contato com informações que podem, pelo lado do capital, garantir a produção ao acionar estas informações com criatividade.

Nesse sentido, o trabalhador deveria integrar-se a esse universo tendo que, a partir da incorporação de novos conhecimentos, incrementar a produção. 
Caracterizar-se-ia uma necessidade que, diferentemente daquela da produção de tipo taylorista ${ }^{3}$, tornaria a capacidade intelectual do trabalhador o incremento central da produção em geral. ${ }^{4}$

Nesse sentido, a análise da composição técnica e subjetiva da classe operária seria, para Lazzarato, o meio para avaliar as dimensões da exploração do trabalho hoje. Abrem-se, pelo menos, dois caminhos para esta análise. Por um lado, esta exploração estaria relacionada ao "conteúdo informacional" da mercadoria, ou seja, "à capacidade de processamento da informação e da comunicação horizontal e vertical" pelo trabalhador coletivo (LAZZARATO, 1992, p. 54) e, por outro, ela estaria relacionada às atividades que produzem o "conteúdo cultural" da mercadoria.

Entretanto, Lazzarato parece ir muito rápido na sugestão de que esse novo tipo de exploração da força de trabalho salvaguardaria uma chave para a formação de uma política socialista e revolucionária. Conseqüentemente, percebemos que suas conclusões estão vinculas à idéia de que, a partir do contato travado por esse núcleo de trabalhadores requalificados com a informação necessária à execução de suas tarefas, supostamente de ordem intelectual, existiria algum componente libertário.

Na prática, Lazzarato comete os mesmos equívocos que, por exemplo, Serge Mallet (1969) cometeu quando afirmou o caráter revolucionário do operário politécnico proveniente da aquisição de qualificações técnicas e científicas adquiridos no processo de automação da produção.

Contrariamente, as teses sobre a constituição do operariado em classe e

\footnotetext{
${ }^{3}$ Longe de fazermos uma exposição reduzida da produção taylorista ou fordista ao caracterizá-las como uma produção na qual o trabalhador estaria despojado de sua dimensão intelectual e em que sua subjetividade não fosse reclamada pelo capital, acreditamos que, na prática, a dimensão intelectual nunca pode ser racionalizada a ponto de ser totalmente dissolvida. A questão é que Lazzarato, ao afirmar a tendência de uma produção e de um trabalho imaterial, percebe que nesse momento a subjetividade e a dimensão intelectual do trabalhador são trazidas à tona, tornandose, dessa forma, pressupostos básicos da produção. De um lado, a produção taylorista tentava progressivamente pulverizar qualquer forma de expressão intelectual do trabalhador ao submetêlo a uma racionalização da produção voraz, que o condicionava como uma máquina viva. Por outro, a produção imaterial que Lazzarato define faz da dimensão intelectual meio de valorização do capital. Valeria precisar como essa subjetividade seria utilizada hoje.

${ }^{4}$ Como nos lembra Marx (1985, p. 109), ao analisar o trabalho em seu núcleo comum, o valor é parte alíquota, do total de mercadorias produzidas pelo operário, que não é paga pelo capitalista.
} 
sobre a formação de uma política socialista não podem ser entendidas com base em formulações desvinculadas de um plano conjuntural e histórico, já que a incorporação de informações no processo produtivo é racionalizada e obedece a interesses materiais específicos.

A análise de Lazzarato está fundamentada no pressuposto de que 0 trabalhador (sua subjetividade) constitui-se com base em sua atividade profissional. Reduz-se toda a formação política e cultural do operariado à sua capacidade profissional dentro da divisão técnica do trabalho. Apenas a existência de uma base material, de uma estrutura econômica que diferencie uma relação social antagônica entre proprietários e não-proprietários não justifica a tese de que todo o processo de organização política do operariado seja fruto somente dessa relação. Esta última é sim o ponto de partida de uma análise que deve confrontar outros vários elementos políticos, sociais e econômicos que, na verdade, estabelecem características específicas à luta de classes em determinados momentos históricos.

Diante disso, vemos a necessidade de apresentarmos uma discussão que procure estabelecer os nexos centrais entre a utilização de uma força de trabalho qualificada e as relações dessa força de trabalho (desse coletivo de trabalhadores), que assimile informações necessárias à ativação da produção imaterial, com possíveis formas de resistência provenientes desse contato. Mostra-se, assim, a urgência em verificar quais seriam as atuais contradições sociais que essa nova forma de trabalho caracterizaria.

Dessa maneira, concordamos com a perspectiva teórica que defende que as novas formas de utilização da força de trabalho trazem também novos antagonismos sociais que podem servir como fundamento da resistência da classe trabalhadora. Mas, daí afirmarmos que novas estratégias de organização da força de trabalho e a introdução de novas tecnologias (a revolução informacional) acionariam a criatividade do trabalhador, possibilitando a constituição de um núcleo combativo, seria, no mínimo, imprudente.

De toda forma, a informação (como produto da força de trabalho) apareceria como uma mercadoria altamente valorizante. Sua importância poderia determinar um momento particular da luta de classes que poderia fazer crescer a resistência da classe trabalhadora, pelo menos em relação a uma luta corporativa, pois abriria novas possibilidades do trabalhador de, a lidar com essas informações, capacitar-se profissionalmente. 
Assim, devemos analisar a efetivação ou não de uma cultura proletária, a partir das novas possibilidades materiais que são abertas no quadro da organização da produção social que se apresenta em uma determinada conjuntura política e social. Nesse sentido, a informação sociabilizada seria uma fonte de incremento da capacidade de luta política da classe trabalhadora, mas viria também marcada por limites que sancionam e determinam a reprodução das relações sociais capitalistas.

A informação absorvida ainda seria determinada pela unidade antagônica da relação capital/trabalho. A incorporação dessa informação propiciada por esse tipo de produção não garante, como não garantiu historicamente, a formação de um sujeito revolucionário.

Para além disso, a questão deve ser retida a partir da idéia de que tais incorporações tecnológicas e gerenciais produzem novas contradições sociais na esfera da produção, mas não garantem a formação de uma classe trabalhadora revolucionária, já que essas contradições são incompatíveis inclusive com as promessas de eqüidade contidas na ideologia do progresso técnico do trabalho e da produção.

Nesse sentido, uma das questões centrais para esse debate é de quais seriam os limites da incorporação de novas formas de gestão da produção e de novas tecnologias, já que simultaneamente ao aumento da produtividade do capital diminuem as possibilidades de autonomização do trabalhador frente às imposições econômicas, políticas e sociais ativadas pelo capital.

\section{Grupos Funcionais e Luta de Classes: FUNCIONALISMO E MARXISMO NA DEFINIÇÃO DAS CLASSES SOCIAIS}

Chegamos aqui a uma outra teoria sobre a classe social revolucionária. Teoria essa que realiza uma separação entre grupos funcionais (presentes no capitalismo) e classes sociais (presentes na transição ao socialismo). Para Décio Saes (2003), não existiria a possibilidade de um grupo funcional, imerso na estrutura social capitalista, (trans)formar-se em uma classe social5. 0 surgimento

\footnotetext{
${ }^{5}$ Segundo Saes (2003, p. 203), não se poderia atribuir nem "uma mesma base física aos grupos de cada sistema que se correspondem por estarem ligados a um mesmo lugar do processo de produção, já que a diferença entre os objetivos peculiares a um e outro sistema de agregação social
} 
das classes sociais apenas tornar-se-ia possível na medida em que um fator externo de ordem econômica as constitui.

Com a iniciativa de refutar os preceitos da análise evolucionista-identitária ${ }^{6}$, Saes lança mão de um argumento central para a análise da constituição do operariado em classe. 0 capitalismo, como em qualquer estrutura produtiva précapitalista baseada na exploração do trabalho, seria um sistema no qual grupos funcionais entram em conflito com o objetivo de reproduzir suas relações de produção. Esses grupos visam apenas à repartição da renda. Não havendo, então, possibilidade de nos referirmos a uma determinação social de classe.

Nesse sistemaeconômico ordenado, os grupos de proprietários (proprietários dos meios de produção e dos meios de circulação, por exemplo) entram em confronto pela repartição da mais-valia total extraída da exploração do trabalho e teriam, em seu conjunto, interesses distintos dos grupos de não-proprietários que, da mesma forma, atuam apenas no sentido de reproduzir as relações de produção existentes, na medida em que lutam somente pela repartição da renda.

Aestruturaeconômicae aestruturajurídico-política (Estado) reproduziriam as relações de produção capitalistas, assegurando a reprodutibilidade das relações de dominação e o controle dos grupos sociais de não-proprietários, isto é, a estrutura econômica imporia a necessidade dos trabalhadores em vender a sua força de trabalho, e a estrutura jurídico-política representaria e imporia legitimamente a manutenção desse estado de coisas. Assim, a estrutura social, em seu sistema autoreprodutivo, tenderia a se reproduzir-se indefinidamente.

No entanto, como seria possível indicar o surgimento das classes sociais e em especial de uma classe revolucionária dentro de uma reprodução social sistêmica? A resposta, já introduzida no primeiro parágrafo desse item, só pode ser dada se pensarmos um elemento externo ao sistema, uma força que criaria as condições objetivas para o "aparecimento" das classes sociais e do antagonismo entre elas.

tende a provocar uma cisão no contingente físico dos ocupantes do mesmo lugar no processo de produçã̃o".

${ }^{6}$ A meu ver Saes (2003, p. 203), refere-se principalmente às teses de Georg Lukács sobre as formas da consciência de classe. Para Lukács, em um estágio a classe trabalhadora teria uma consciência contingente, isto é, "em si", que a impediria de reconhece-se como sujeito histórico. Em um momento posterior, adquiriria uma consciência política "coesa que estaria voltada sistematicamente para a destruição das relações de produção vigentes". 
Para Saes, é necessário que o processo de reprodução funcional dê lugar a uma luta direta entre proprietários e não-proprietários. Isto requereria a constituição de um momento histórico particular no qual o Estado não pudesse mais representar os interesses dos grupos dominantes, no qual haja uma,

[...] cessação da operação dos efeitos ideológicos sobre os agentes [produtivos]. Isso significa que, [...], o trabalhador passa da submissão prática ao lugar por ele especificamente ocupado no processo de produção à negação prática das relações de produção vigentes [...]. Nos processos de transição, portanto, surgem grupos sociais disputando diretamente - e de modo irreconciliável - a preservação ou a destruição das relações de produção vigentes: são as classes sociais em luta" (SAES, 2003, p. 207 - grifos meus).

Mas, voltemos à questão central: qual é o elemento ou o conjunto de elementos essenciais para a configuração desse momento histórico? Qual é o fator que cria possibilidades objetivas para o surgimento de classes sociais antagônicas e, em conseqüência, para a preservação ou destruição das relações de produção capitalistas?

Esse elemento, para Saes, não só para a sociedade capitalista, mas também para as pré-capitalistas, é o desenvolvimento das forças produtivas. Esse desenvolvimento faria com que a classe trabalhadora tomasse corpo, surgisse e, assim, pudesse exercer uma ação negativa e direta em relação à dominação que lhe é imposta pela classe capitalista representada pela estrutura jurídico-política dominante. Contudo, dever-se-ia conferir a este movimento econômico uma nova abrangência.

[...] abarcar não só o processo, típico do capitalismo, de desenvolvimento das forças produtivas (inovações tecnológicas, organizacionais etc.) como também o processo, típico de economias pré-capitalistas, de mercantilização de economias naturais, mesmo no caso de tal processo não ser acompanhado de algum importante desenvolvimento das forças produtivas. Transformações econômicas de um ou de outro desses dois tipos, por repercutirem em cadeia e influenciarem os diversos elementos componentes do sistema econômico, permitem que os grupos em situação subalterna no processo de produção visualizem finalmente a relação entre a sua situação a as características gerais do sistema econômico, rompendo-se assim o círculo vicioso da submissão ideológica" (SAES, 2003, p. 207).

0 desenvolvimento das forças produtivas é então concebido por Saes como algo que está à margem da estrutura social. Teria, assim, uma dinâmica própria 
que, num determinado momento de seu desenvolvimento, ativaria o processo de constituição do operariado em classe. Um elemento exterior ao sistema autoreprodutivo e funcional - as forças produtivas - é considerado por Saes como central para pensar a superação da estrutura social capitalista, já que apenas a partir de sua ativação tornar-se-ia possível o surgimento das classes e do embate direto entre elas, isto é, a luta de classes.

Portanto, tal análise estabelece que as sociedades organizadas com base na exploração do trabalho estariam fadadas a uma mutação que tem como prerrogativa 0 avança autônomo das forças produtivas. Saes indica haver dois sistemas: o sistema funcional e o sistema antagonístico e informa que não há relação entre eles e, tampouco, entre seus agentes políticos. De um lado, estariam os grupos funcionais em disputa pela repartição da renda; de outro, a classe social, apta a destruir, ou pelo menos tentar destruir, com base em uma luta consciente, 0 sistema antagonístico.

As ações sociais girariam no sistema funcional, como Saes bem salienta, em torno de interesses apenas voltados para repartição da renda. A resistência do operariado, as conquistas políticas, as questões regionais, a formação política Estatal, etc. seriam irrelevantes para a definição de uma classe revolucionária ou para a possibilidade de seu "aparecimento".

Dentro deste quadro teórico, Saes relaciona o surgimento do agente da revolução socialista às formas mais avançadas das forças produtivas em presença. Recorrendo às teses de Lojkine (1992), indica a revolução informacional como agente "precipitador" da luta de classes, isto é, de que o caráter social desta revolução poderia caracterizar o rompimento com a ordem funcional da sociedade capitalista.

As novas formas de produção ativadas pelo proletariado da informática não estariam inseridas no processo de reprodutibilidade das relações de produção; pelo contrário, elas seriam um elemento, em seu conjunto, autônomo ao sistema que poderia, por fim, colocá-lo em cheque.

Vê-se, mais uma vez, o desdobramento das teses sobre o desenvolvimento das forças produtivas, expostas no Manifesto Comunista, ganhar uma dimensão economicista no processo de definição do operariado em classe. Aproximam-se, dessa forma, três formas de entendimento (Serge Mallet, Maurízio Lazzarato e Décio Saes), cada qual com suas peculiaridades, sobre a transição e a formação (surgimento no caso de Saes) das classes e da luta de classes preso a uma 
determinação a-histórica que suprime as possibilidades de intervenção direta de sujeitos sociais, esvaziando, assim, as relações de força travadas no cotidiano de reivindicações partidárias e sindicais, jurídicas e ideológicas em formações sociais específicas.

\section{Conclusão}

$\mathrm{Na}$ introdução, firmei a posição de que uma corrente dominante da literatura marxista, durante o século XX e princípio do XXI, teria desenvolvido, com base na tese da determinação das forças produtivas sobre as relações de produção expostas no Manifesto Comunista de Marx e Engels, a difusão do tema da transição ao socialismo e da formação do operariado em classe e que essa perspectiva adotada seria determinista no que se refere às técnicas de produção e às qualificações profissionais.

É necessário dizer que a problemática desenvolvida por Marx e Engels no Manifesto é muito mais complexa e aborda pelo menos dois grandes blocos. Para Marx e Engels, a questão da transição e da formação do operariado em classe deveria levar em conta, primeiro, o avanço das forças produtivas e, segundo, a luta de classes de uma determinada conjuntura e momento histórico específicos, isto é, dentro da estrutura geral caracterizada pela relação entre forças produtivas/ relações de produção e classes e lutas de classes/Estado.

0 que quero salientar aqui é que na maioria das vezes a literatura marxista que discutiu a deflagração da classe revolucionária e das possibilidades de transição ao socialismo com base no desenvolvimento autônomo das forças produtivas, negligenciou a luta de classes de suas formulações analíticas. Isto acabou por conferir a elas uma perspectiva da história que desvincula a luta de classes das ações políticas das classes em presença, dando à dinâmica das forças produtivas uma racionalidade supra-histórica no processo de efetivação das condições objetivas da revolução socialista considerada.

Deve-se sublinhar que no Manifesto do Partido Comunista a problemática da luta de classes e do avanço das forças produtivas não estão desvinculados. Marx e Engels não deixam nenhuma dúvida quando insistem que a Alemanha seria 0 país mais propício para a efetivação de uma revolução proletária e não a Inglaterra (país onde as forças produtivas estavam mais desenvolvidas naquele momento).

É sobretudo para a Alemanha que os comunistas voltam sua atenção, porque a Alemanha se encontra às vésperas de uma revolução burguesa, porque 
realizaráessa revolução nas condições mais avançadas da civilização européia, com um proletariado muito mais desenvolvido do que o da Inglaterra do séc. XVII e o da França do séc. XVIII, e por que a revolução burguesa alemã só poderá ser 0 imediato do prelúdio de uma revolução proletária" (MARX; ENGELS, 1996, p. 99).

Nesse sentido, Marx e Engels deixam clara a necessidade de entender 0 processo de formação do operariado com base em determinações de ordem política. A Alemanha, nesse momento, poderia, assim, ser considerada dentro da estrutura capitalista européia como o elo mais fraco. A revolução burguesa poderia, então, segundo Marx e Engels, abrir um contexto no qual possibilidades políticas e materiais para a revolução proletária estivessem presentes. 0 desenvolvimento do contingente de trabalhadores e da maquinaria seriam, dessa forma, uma parte dos fatores a serem considerados, mas não os centrais.

0 avanço das forças produtivas abre, a cada novo momento de seu desenvolvimento, novas formas de controle e dominação da classe trabalhadora. No entanto, deve-se destacar também que, ao mesmo tempo em que são abertas novas frentes de exploração da classe trabalhadora, abrem-se novas possibilidades na cadeia de reprodutibilidade das relações de produção que podem mudar o quadro estrutural da sociedade: o nível de organização e a correlação de forças que a classe trabalhadora trava com as classes dominantes em um determinado período devem ser precisados.

Além disso, o avanço das forças produtivas é fruto, ele mesmo, das lutas entre as classes trabalhadoras e capitalistas. A ampliação das possibilidades de dominação que caracterizam o desenvolvimento ou a estagnação das forças produtivas não é automática. Pelo contrário, essa ampliação é, na prática, a própria concretização do embate entre interesses distintos, entre visões de mundo que se chocam direta e indiretamente na história.

Ao abrir a discussão sobre a constituição do proletariado em classe no Manifesto Comunista, Boito Jr. (1998, p. 115) salienta que "o processo de mudança histórica é apresentado, neste texto [0 Manifesto], como resultado do crescimento das forças produtivas e da luta de classes", ou seja, haveria, segundo Boito, uma dupla interferência, de um lado, as forças produtivas, de outro, a luta de classes.

Esses dois fatores influenciam-se reciprocamente e de diversas maneiras. De um lado, o desenvolvimento das forças produtivas pode produzir novas classes sociais e alterar a base econômica das classes em luta. 0 Manifesto 
nos mostra que o desenvolvimento da maquinaria e da grande indústria fortalece a classe burguesa, faz crescer o proletariado e arruína 0 artesanato e a pequena burguesia tradicional. De outro lado, a luta de classes interfere nas características e no ritmo de crescimento das forças produtivas (BOITO JR, 1998, p. 115).

A interferência das lutas sociais no desenvolvimento das forças produtivas é fundamental para a caracterização da formação da classe revolucionária. No entanto, tal problemática parece ainda fundamentar-se em certa dicotomia caracterizada pela relação entre o desenvolvimento das forças produtivas e a luta de classes. Acreditamos que a crítica deveria ir mais além, ou seja, examinar as forças produtivas, sua interferência no processo de constituição do proletariado em classe, caracterizando-a como uma expressão da luta de classes.

Dessa forma, não seria possível afirmar qualquer tipo de autonomia das forças produtivas em relação à luta de classes. As classes em presença informariam na sua luta contra a dominação capitalista, o conjunto de resoluções políticas, econômicas e sociais, ativando suas formas de existência, reprodução ou destruição da base material que as informam reciprocamente. 0 desenvolvimento lento ou acelerado das forças produtivas capitalistas depende, portanto, da relação entre interesses opostos que se relacionam.

\section{REFERÊNCIAS}

B0IT0 JR., Armando. A constituição do proletariado em classe, a propósito do Manifesto Comunista de Marx e Engels. Crítica Marxista, n. 6, Campinas,1998, p. 115-125.

BRAVERMAN, Harry. Trabalbo e Capital Monopolista: a degradação do trabalho no Século XX. Rio de Janeiro: Zahar, 1980.

LAZZARATO, Maurizio. Le Cycle de la Production Immatériel. Futur Antérieur, n. 16, Paris, 1993, p.111-120.

Le Concept de Travail Immatériel. Futur Antérieur, n. 10, Paris, 1992, p. 114.

LOJKINE, Jean. A Revolução Informacional. São Paulo: Cortez, 1992. 
MALLET, Serge. Le Pouvoir Ouvrier: bureaucratie ou democratie ouvrière. Paris: Anthropos, 1971.

. La Nouvelle Classe Ouvrière. Paris: Éditions du Seuil, 1969.

MARGLIN, Sthepen. Origem e funções do parcelamento das tarefas (para que servem os patrões?). In: GORZ, André (org.). Crítica da Divisão do Trabalho. São Paulo: Martins Fontes, 1996. p. 37-77.

MARX, Karl; ENGELS, Friedrich. Manifesto do Partido Comunista. Petrópolis: Vozes, 1996.

MARX, Karl. Capítulo VI Inédito de O Capital: resultados do processo de produção imediata. São Paulo: Moraes, 1983. p. 133-140.

NEGRI, Toni; VINCENT, Jean-Marie. Paradoxes autour du travail. Futur Antérieur, n. 10, Paris, 1992, p. 5-8.

SAES, Décio. Considerações sobre a análise dos sistemas de classe. In: BOITO JR, Armando et alli. Marxismo e Ciências Humanas. São Paulo: Xamã, 2003.

TOSEL, André. Centralité et non-centralité du travail ou la passion des hommes superflus. In: BIDET, Jaques; TEXIER, Jaques. La Crise du Travail. Paris: PUF, 1994. p. 209-218.

VINCENT, Jean M. Les automatismes sociaux et le 'général intellect'. Futur Antérieur, n. 16, Paris,1993, p. 121-130. 